\title{
Retreatability of Bioceramic Endodontic Sealers: a Review
}

\author{
Kostadin I. Zhekov, Vessela P. Stefanova \\ Department of Operative Dentistry and Endodontics, Faculty of Dental Medicine, Medical University of Plovdiv, Plovdiv, Bulgaria \\ Corresponding author: Kostadin Zhekov, Department of Operative Dentistry and Endodontics, Faculty of Dental Medicine, Medical University of \\ Plovdiv, 3 Hristo Botev Blvd., 4002 Plovdiv; E-mail: ko.zhekov@gmail.com; Tel.: +359885995821
}

Received: 28 Oct 2019 Accepted: 26 Dec 2019 Published: 30 June 2020

Citation: Zhekov KI, Stefanova VP. Retreatability of bioceramic endodontic sealers: a review. Folia Med (Plovdiv) 2020;62(2):258-64. doi: 10.3897/folmed.62.e47690.

\begin{abstract}
In 2009 a new type of endodontic sealers was introduced to the market. The so called "bioceramic" sealers are a promising alternative to the present golden standard of root canal fillings. Now a decade later, still very little is known about the ability to remove these sealers in cases of non-surgical endodontic retreatment (NSER). There are only a limited number of articles that provide such information. The commonly used hand files are not efficient in removing thoroughly the sealer from the main canal walls. Machine driven files are much easier and faster alternative to the hand ones, but are still not able to ensure complete removal. Although ultrasonics can be applied only in the straight portion of the main canal, they raise the efficacy of sealer removal. Photon-initiated photoacoustic streaming (PIPS) is another way to enhance the removal of bioceramics. Solvents like chloroform and orange oil are effective in softening gutta-percha, but not the bioceramics. This article reviews the available scientific data concerning removal of bioceramic materials in the context of a NSER.
\end{abstract}

\section{Keywords}

bioceramics, retreatment, review

\section{INTRODUCTION}

It has been nearly a decade since bioceramic endodontic sealers (BCS) were introduced to the market. After the development of mineral trioxide aggregate (MTA) by Torabinejad in 1993, endodontics itself experienced a paradigm shift. ${ }^{1}$ Teeth that were once indicated for extraction could now be saved in the most conservative manner, due to the biocompatibility and exceptional mechanical properties of this new material. Based on the tricalcium-silicate technology, benefited from MTA, the bioceramic sealers possess numerous qualities and their use is becoming more and more popular. They are biocompatible, give high $\mathrm{pH}$, ensure a tight seal, and are non-soluble after setting. These sealers are indicated to be used as sealers in conjunction with a core material and not as root filling materials. There is one big unsolved problem, though, that prevents many experienced clinicians from using them - they bind to the canal walls so well that the ability to be removed in cases of endodontic failure and consecutive retreatment is concerning. In 1987, Wilcox et al. noticed that most of the remaining material during retreatment was actually sealer which should be completely removed in order to influence the periapical inflammation. ${ }^{2}$ There are no reports in the available literature that review the different approaches to remove bioceramic sealers during non-surgical endodontic retreatment.

\section{AIM}

The aim of this article is to review the techniques and materials used to remove bioceramic sealers from the main canal walls. An overview of the available scientific data was done using the PubMed search engine and other sources with "retreatment" and "bioceramics" as keywords. A total of 20 articles were found, and these are discussed below.

In order to sort the data, we divided the results accord-

Copyright by authors. This is an open access article distributed under the terms of the Creative Commons Attribution License (CC-BY 4.0), 
ing to the equipment used in removal of the root canal filling. Some of the authors investigated the efficacy of different machine driven endodontic files systems. Others counted on the usage of a solvent to facilitate the removal of the filling. In some studies ultrasonic tips were used in conjunction with endodontic files as an additional tool for root filling removal. Activation of the irrigant by different means has also been tested to facilitate sealer removal.

\section{MACHINE-DRIVEN ENDODONTIC FILES}

All experiments of removing bioceramic sealers in the context of NSER use a form of machine driven files to enhance the efficacy and lessen the time needed to remove the root canal filling. In this group we have discussed the articles that present only the use of endodontic files - hand- and machine-driven, to complete the NSER. No solvents, ultrasonic or laser energy are used in this group of studies.

The first study in this group aims to evaluate residual root filling material following removal of three newly developed root canal sealers used with a matched-taper single-cone root filling technique and to compare the efficacy of ProTaper Universal rotary retreatment instruments (Dentsply Maillefer, Ballaigues, Switzerland) with that of a conventional manual technique. Four types of endodontic sealers are included in the study - one polymeric (Hybrid Root SEAL, Sun Medical Co Ltd., Shiga, Japan; Parkell Inc., Edgewood, NY, USA), one glass-ionomer (Activ GP system, Brasseler USA, Savannah, GA, USA), one epoxy based (AH Plus, Dentsply International Inc., York, PA, USA) and one bioceramic (EndoSequence BC Sealer, Brasseler USA). The quantity of remaining material was evaluated using radiographs in different angulations and a specialised software (Image image analysis software, National Institutes of Health, Bethesda, MD, USA). Significantly more remaining filling material was observed in the apical third $(p<0.05)$. In conclusion, there was no statistical difference between the efficacy of machine driven and hand files in the removal of sealer. $^{3}$

Another study took place in Turkey in 2015. The authors used again the ProTaper Universal Retreatment (PTR) system to evaluate the retreatability of root canals obturated with three different endodontic sealers - iRoot SP (bioceramic sealer), MTA Fillapex (MTA-based sealer) and AH26 (epoxy resin-based sealer). They used two different cold techniques for root canal obturation - single cone matched taper technique and lateral condensation. The time taken to reach the working-length (TWL) was recorded. Roots were longitudinally sectioned and each half was evaluated using a stereo-microscope. Three observers scored each third of all specimen. Complete removal of material from canal walls was not achieved in any of the groups. All the groups showed more remnants of material in the coronal part of the canal, compared to the middle and apical. MTA Fillapex took the least time to be removed and showed biggest amount of remnants. ${ }^{4}$
Kim et al. examined the remnants of obturation material and depth of penetration of sealer using confocal microscopy (LSM 780; Zeiss, Jena, Germany). For removal of the root filling material they used two different rotary systems - Gates Glidden and ProFile (Dentsply Maillefer, Ballaigues, Switzerland). Teeth were divided into 2 groups based on the type of sealer used during the root filling procedure: group $1(\mathrm{n}=13)$ (AH Plus sealer) and group $2(\mathrm{n}=15)$ (EndoSequence BC sealer). Both sealers were mixed with rhodamine B (Sigma-Aldrich, St Louis, MO) for fluorescence. Results showed that there was no significant difference in retreatment time between the two groups. Canal patency was achieved in all specimens, although obturation material remnants were found in each of the groups. No statistical difference was found regarding the type of sealer. As for the penetration depth of sealer, the only significant difference was found in the portion $6 \mathrm{~mm}$ from the apex where the resin sealer showed better penetration. ${ }^{5}$

In 2018, Kakoura et al. evaluated the residual filling material and the reestablishment of working length (WL) and apical patency (AP) after retreatment of BioRoot RCS, compared to TotalFill BC Sealer (FKG Dentaire SA, La Chauxde-Fonds, Switzerland) and AH26 (Dentsply Maillefer, Tulsa, USA). The groups consisted of 20 canines, shaped and obturated by the single cone matched taper technique (hydraulic condensation). Removal of the filling started with PTR (Dentsply Maillefer, Ballaigues, Switzerland) D1, D2, and D3 files and finished with 50/.04 (Sendoline, Täby, Sweden). After longitudinal separation of the samples they were observed at magnification of $\times 100$ and $\times 1000$ (SEM) and the type of residual material was determined by EDS (energy dispersive spectrometry, Inca software, Oxford, UK). WL and AP were achieved in $95 \%$ of the cases with AH26 and in 100\% in the groups of TotalFill and BioRoot. Remnants of filling material were found in each specimen of each group. Kruskal-Wallis test showed no statistical difference in the remaining material between the groups as well as between coronal, middle or apical third of the canal $(p>0.05){ }^{6}$

The same year in Germany, Donnermeyer et al. compared the ability to remove three calcium-silicate sealers (BioRoot RCS, MTA Fillapex, Endo C.P.M.) and one epoxy - AH Plus, using different instruments (Hedström files, Reciproc R40, Mtwo retreatment file R 25/.05 + Mtwo 40/.06, and F6 SkyTaper). The criteria evaluated in the experiment were quantity of remaining material and time required for retreatment. After the retreatment procedure samples $(n=192)$ were sectioned longitudinally and captioned by a digital camera (Alpha NEX-5; Sony, Tokyo, Japan) under $\times 8$ magnification (Zeiss Pico; Oberkochen, Germany). Images were transferred to an imaging software (ImageJ; Wayne Rasband, NIH, MD, USA) and the amount of residual sealer on the root canal walls was calculated in percentages. The authors concluded that canals containing calcium-silicate sealers revealed less residual material on the walls and required less time to retreat than AH Plus. Machine-driven files did better than the hand $\mathrm{H}$-files in re- 
moving root canal fillings. ${ }^{7}$

The latest study in this group was conducted in August 2019. Its aim was 2 -fold: to evaluate the penetration of a tricalcium silicate-based endodontic sealer (EndoSequence BC Sealer; Brasseler USA, Savannah, GA) into dentinal tubules without a core material (sealer) or with 0.02 or 0.04 tapered bioceramic gutta-percha points and to compare the time required to remove the root fillings. The authors used confocal laser scanning microscopy (LSM Pascal; Carl Zeiss, Jena, Germany) at magnification of $\times 2.5$ with a 543-nm wavelength of a helium laser and LSM Image Examiner Software (Carl Zeiss) to evaluate the penetration of the sealer. For the retreatment experiments the root fillings were removed with ProTaper Retreatment files D1, D2, and D3 (Dentsply Tulsa Dental, Tulsa, OK). The use of BC Sealer with a 0.04 taper gutta-percha point yielded the highest percentage and area of penetration, whereas no difference was found between the 0.02 taper gutta-percha and the sealer alone groups. Both the 0.02 and 0.04 taper groups required a similar time to reach the working length. In the sealer alone group the working length could not be achieved. ${ }^{8}$

\section{SOLVENTS}

In this group three studies examine the effect of facilitating bioceramic sealers removal with the help of a solvent.

The first study is by Hess et al. who investigated the ability to regain WL and AP when using the recently developed at the time (2011) BC Sealer (Brasseler USA, Savannah, GA). The purpose of this study was to evaluate the efficacy of solvent and rotary instrumentation in the removal of BCS when used in combination with gutta-percha (GP) as compared with AH Plus sealer (Dentsply, Tulsa, OK). The ability to regain the $\mathrm{WL}$ and patency were evaluated as well as the time required to remove obturation material. Representative samples were also analyzed via scanning electron microscopy. Canals were obturated with either GP/AH Plus with warm vertical compaction or GP/BCS using a single cone. The groups were subdivided into samples with the master GP cone placed to the working length or intentionally $2 \mathrm{~mm}$ short of the WL. Canals were then retreated using heat, chloroform, rotary instruments, and hand files. An activated System B 0.06-tapered plugger (SybronEndo, Orange, CA) was introduced at $200^{\circ} \mathrm{C}$ to resistance and withdrawn to remove coronal obturation material. Three to 4 drops of chloroform were then introduced into the reservoir and rotary files were used in a crown-down technique. Small hand files (C-Files, C+ Files, and Flexofiles sizes 6, 8 , and 10, Dentsply) were used in an attempt to penetrate or bypass blockages. The WL was not regained in $70 \%$ of samples with BCS/master cone short of the WL. Patency was not re-established in $20 \%$ of samples with BCS/master cone to the WL or in $70 \%$ of samples with BCS/master cone short of the WL. However, in 30\% of these samples $\mathrm{WL}$ and AP were regained and the latter is explained by the existence of voids in the material and possible improper setting. The authors concluded that conventional retreatment techniques were not able to fully remove BCS. The tested techniques proved ineffective in some samples in their study, which indicates the need for a new technique or solvent to be developed. ${ }^{9}$

In 2014, Carpenter et al. studied the effects of the solvents commonly used during endodontic retreatments on this new type of sealers. The sealer used in their study was MTA Fillapex (Angelus Solucoes Odontologicas, Londrina PR, Brazil), which consisted of about $40 \%$ MTA and resin. ${ }^{10}$ They prepared two groups of single rooted teeth. The first group ( $\mathrm{n}=43$ ) was obturated at working length and the second group $(n=43)$ was obturated $2 \mathrm{~mm}$ shorter. The obturation technique used was the continuous wave of obturation. The two big groups are subdivided into smaller groups according to the solvent: group A - chloroform $(n=10)$, group B - Endosolv R (Septodont, France) $(n=10)$, group $\mathrm{C}$ - Endosolv $\mathrm{E}$ (Septodont, France) $(\mathrm{n}=10)$, group $\mathrm{D}$ - Eucalyptol $(n=10)$, group $E$ - no solvent $(n=3)$. The conclusions were that chloroform, Eucalyptol and Endosolv E were effective at softening gutta-percha and MTA Fillapex, whereas Endosolv R was not. This might be explained by the nature of the sealer. ${ }^{11}$

De Sequeira Zuolo et al. conducted a study in 2016 in which they compared the efficacy of rotary versus reciprocating systems in the removal of filling material from oval canals filled with 2 different sealers and also looked for differences in the working time. The systems they chose were TRUShape (Dentsply Tulsa Dental Specialties, Tulsa, OK) and Reciproc (VDW, Munich, Germany) and the sealers were Pulp Canal Sealer EWT (Sybron Dental Specialties, Orange, CA) and Endosequence BC Sealer (Brassler, Savannah, GA). After the initial retreatment protocol with Gates-Glidden burs they placed $0.1 \mathrm{~mL}$ chloroform into the canal for 30 seconds to soften the gutta-percha. No significant differences in gutta-percha and sealer removal were found between TRUShape and Reciproc files. However, the groups that were filled with Pulp Canal Sealer exhibited less remaining filling material than the groups that had been filled with BCS. Irrespective of the technique used, all of the samples exhibited residual filling material in the canal space. Filling material removal was significantly shorter in the groups of Reciproc files. The roots that had been filled with BCS also required more time for retreatment than those that had been filled with PCS $(p<0.05) .{ }^{12}$

In 2017, Oltra et al. analysed the volume of residual material after retreatment of two types of sealers - one bioceramic Endosequence BC Sealer (Brasseler, Savannah, USA) and one epoxy - AH Plus (Dentsply, Tulsa, OK) using micro-CT scans. They use Vortex Blue (Dentsply, Tulsa Dental Specialties, Tulsa, OK, USA) and chloroform in the retreatment technique. The results of this study demonstrated that the BC Sealer group had significantly more residual filling material than the $\mathrm{AH}$ Plus group regardless of whether or not both sealers were retreated with chloroform. ${ }^{13}$ 


\section{ULTRASONIC TIPS}

Simsek et al. published a study in 2014, performed on 60 extracted human single-rooted premolars. All the canals are obturated by cold lateral compaction technique with gutta-percha and sealer. The aim of this study was to evaluate the effectiveness, in terms of the operating time and scanning electron microscopy (SEM) results, of two different retreatment techniques (ESI ultrasonic tips and R-Endo files) in removing three different sealers - AH Plus (Denstply DeTrey, Konstanz, Germany), MM Seal (Micro-Mega, Besançon, France) and iRoot SP (Innovative BioCeramix Inc., Vancouver, Canada). To soften the gutta-percha, 0.1 $\mathrm{mL}$ of chloroform was applied to and kept in the coronal third for $1 \mathrm{~min}$ after initial removal of coronal root filling by Gates Glidden burs. R-Endo files were used in sequence until WL was reached. ESI ultrasonic tips of different sizes were used in a circumferential motion until the WL was achieved. Both R-Endo and ultrasonic tips performed similarly in terms of operating time. All of the retreatment techniques left remnants, regardless of the type of sealer. In all groups, apical tubules were less clear than other parts of the root. ${ }^{14}$

In 2015, Agrafioti et al. studied the re-establishment of apical patency after obturation with gutta-percha and two novel calcium silicate based sealers - TotalFill BC Sealer and MTA Fillapex, versus AH Plus as a golden standard. They used the canals of 54 single-rooted anterior teeth with wide and straight canals. In the retreatment technique they started with ultrasonic tips (BL1, B \& L Biotech USA Inc., Philadelphia, USA) for the initial penetration and then used reciprocating (Wave One), rotary (Race) and hand $(\mathrm{C}+)$ files in conjunction with chloroform. Assessment of the residue was observed under dental optical microscope (DOM) (Carl Zeiss OPMI Pro Ergo, Germany). They managed to regain WL and AP in $100 \%$ of specimens in all the groups. DOM images of samples revealed filling material remaining in all groups. The most amount of remaining material could be observed in the groups of AH Plus while the least amount - in the groups of MTA Fillapex. The conclusions were that the new calcium silicate based sealers were negotiable when the root canal anatomy was simple. However, with more complex root canal anatomies, such as the ones used by Hess et al. (mesiobuccal roots of mandibular molars), the outcome might be quite different. ${ }^{15}$

In 2018, Marinova-Takorova et al. compared the efficacy of three different retreatment techniques in the removal of gutta-percha and bioceramic-based sealer in the different parts of the root canal. Extracted human single rooted teeth $(n=66)$ were used. The teeth were divided into six groups: Gr1 - retreated using ProTaper Universal Retreatment files after filling with central cone technique; Gr2 - ProTaper Universal Retreatment files after cold lateral compaction technique; Gr3 - hand instruments after central cone filling technique; Gr4 - hand instruments after cold lateral compaction technique; Gr5 - ultrasonic tips after central cone technique; Gr6 - ultrasonic tips after cold lateral condensation. For all groups first Gates Glidden \#3 (Dentsply Maillefer, Bellaigues, Switzerland) was used to remove the gutta-percha in the coronal $2 \mathrm{~mm}$. Then solvent (orange oil) was applied. Residual filling material was evaluated using computed tomography and microscope observation. Best removal of filling material was achieved in the middle part or the root canal and worse in the coronal. When central cone technique was used, best cleaning was observed with hand instruments in the coronal and middle part and with ultrasound in the apical part. There was no statistically significant difference in the coronal and middle third of the canal when lateral compaction technique was used, the ultrasonic tips performed best in the apical part. ${ }^{16}$

The same authors published another study in 2019 to evaluate and compare the time needed and the effectiveness of three different retreatment techniques in the removal of root canal filling material from teeth $(n=33)$ filled with lateral compaction technique and bioceramic based sealer MTA Fillapex (Angelus, Londrine, PR, Brazil). The systems they compared were: Gr1 - ProTaper Universal Retreatment files (Dentsply Maillefer, Bellaigues, Switzerland) (PTUR); Gr2 - hand instruments ( $\mathrm{H}$ files (Dentsply Maillefer, Bellaigues, Switzerland) (HF); Gr3 - ultrasonic tips (EMS, Switzerland \# 20] (UST). Orange oil was applied as solvent after Gates Glidden \#3 was used to remove the gutta-percha in the coronal $2 \mathrm{~mm}$. For residue assessment teeth were sectioned longitudinally and observed under a microscope (Leica M320, Germany) under 16× magnification. Complete removal of filling material was not achieved in any part of any root canal. A significant difference was observed only in the coronal part of the root canals between the PTUR files and the ultrasonic files. No statistically significant difference was observed between different retreatment techniques concerning both their effectiveness and the time needed for the procedure in the other regions of the root canal system. ${ }^{17}$

The same year the same authors published yet another study, with an identical design. The only difference is that this time the canals $(n=33)$ were filled by matched taper single cone technique, instead of lateral compaction. Groups and retreatment techniques were identical to the previous ones. Results showed that none of the tested retreatment techniques succeeded in removing thoroughly the filling material. The worst results were observed when machine rotary files were used. Hand instrumentation performed best. The authors recommend the combined use of machine files with either hand files or ultrasonic tips for achieving better results. The good results with the ultrasound might be explained with its specific action - ultrasonic activation generates a high movement of fluid in a circular action around the vibrating instrument inside the canal space, which leads to better cleaning and dissolving. Its cavitation effect also promotes its efficiency. ${ }^{18}$ 


\section{ASSISTED IRRIGATION}

\section{Laser assisted irrigation}

Suk et al. examined the effect of laser activated (photon-initiated photoacoustic streaming - PIPS) irrigation on the efficacy of removing bioceramic sealer. They used 36 single-rooted human extracted teeth, which were divided in 3 groups according to the sealer used: group 1: EndoSequence BC Sealer (Brassler, USA), group 2: MTA Fillapex (Angelus Solucoes Odontologicas, Londrina, Brasil), and group 3: AH Plus sealer (Dentsply DeTrey, Konstanz, Germany). The filling technique was cold lateral condensation. The retreatment tools include rotary retreatment system ProTaper Universal Retreatment (Maillefer, Ballaigues, Switzerland), followed by Er:YAG laser-activated irrigation (PIPS). No solvent was used. The specimens were scanned in a micro-computed tomographic (micro-CT) device after root canal filling, after the rotary retreatment, and after the PIPS. Using the rotary retreatment technique, the MTA Fillapex was most easily removed from the root canal, and there was no difference between removing the EndoSequence $\mathrm{BC}$ and the epoxy resin material. The authors ob- served significant reduction of the filling remnants after the PIPS in all groups $(p<0.05) .{ }^{19}$

\section{Mechanically assisted irrigation}

Pedulla et al. published a study in 2019 that investigates the retreatability of two calcium silicate-based materials (BioRoot RCS, Septodont, Saint Maur des Fossés, France and Guttaflow Bioseal, Colténe/Whaledent AG, Langenau, Germany) using rotary instrumentation combined with supplementary irrigant agitation techniques using extracted teeth in a laboratory setting. For filling of the canals, a matched taper gutta-percha single cone technique was used. Removal of root filling was performed with rotary instruments and specimens were randomly allocated to one of the subgroups for supplementary irrigant agitation ( $\mathrm{n}=12)$ : subgroup A - syringe irrigation (control); subgroup B - Tornado Brush (M.I.B, Suresnes, France) and subgroup C - ultrasonically activated irrigation. Specimens were re-scanned with micro-CT to calculate the volume of remnant root filling material. The results revealed that there was no significant difference between the supplementary techniques and syringe irrigation in removing Guttaflow Bioseal, while ultrasonic activation

Table 1.

\begin{tabular}{|c|c|c|c|c|c|c|c|c|c|c|}
\hline Authors & Year & $\mathbf{N}$ & $\begin{array}{l}\text { Obturation } \\
\text { technique }\end{array}$ & Bioceramic sealer & $\begin{array}{l}\text { Hand } \\
\text { files }\end{array}$ & $\begin{array}{l}\text { Ma- } \\
\text { chine } \\
\text { files }\end{array}$ & Solvent & US & PIPS & $\begin{array}{c}\text { Tornado } \\
\text { Brush }\end{array}$ \\
\hline 1. Hess D, et al. ${ }^{9}$ & 2011 & 40 & $\begin{array}{l}\text { WARM(CW)/ } \\
\text { COLD }(\mathrm{HC})\end{array}$ & BC Sealer & + & + & + & & & \\
\hline 2. Ersev $\mathrm{H}$, et al. ${ }^{3}$ & 2012 & 120 & $\operatorname{COLD}(\mathrm{HC})$ & BC Sealer & + & + & & & & \\
\hline 3. Simsek N, et al. ${ }^{14}$ & 2014 & 60 & $\operatorname{COLD}(\mathrm{LC})$ & iRoot SP & & + & + & + & & \\
\hline 4. Carpenter MT, et al. ${ }^{11}$ & 2014 & 86 & WARM(CW) & MTAFillapex & + & + & + & + & & \\
\hline 5. Kim H, et al. ${ }^{5}$ & 2015 & 28 & WARM(CW) & BC Sealer & & + & & & & \\
\hline 6. Agrafioti A, et al. ${ }^{15}$ & 2015 & 53 & WARM(CW) & MTA Fillapex, BC Sealer & + & + & + & + & & \\
\hline 7. Uzunoglu E, et al. ${ }^{4}$ & 2015 & 40 & COLD(LC,HC) & iRoot SP, MTA Fillapex & + & + & & & & \\
\hline 8. De Siqueira Zuolo A, et al. ${ }^{12}$ & 2016 & 64 & WARM(CW) & BC Sealer & + & + & + & + & & \\
\hline 9. Oltra E, et al. ${ }^{13}$ & 2017 & 56 & WARM(CW) & BC Sealer & + & + & + & & & \\
\hline 10. Suk M, et al. ${ }^{19}$ & 2017 & 36 & $\operatorname{COLD}(\mathrm{LC})$ & MTA Fillapex, BC Sealer & & + & & & + & \\
\hline 11. Kakoura F, Pantelidou O. ${ }^{6}$ & 2018 & 68 & $\operatorname{COLD}(\mathrm{HC})$ & BioRoot, TotalFill BC & + & + & & & & \\
\hline 12. Donnermeyer D, et al. ${ }^{7}$ & 2018 & 192 & $\operatorname{COLD}(\mathrm{HC})$ & $\begin{array}{l}\text { BioRoot, MTA Fillapex, } \\
\text { Endo C.P.M. }\end{array}$ & + & + & & & & \\
\hline 13. Marinova-Takorova M, et al. ${ }^{16}$ & 2018 & 66 & $\operatorname{COLD}(\mathrm{LC}, \mathrm{HC})$ & MTAFillapex & + & + & + & + & & \\
\hline 14. Marinova-Takorova M, et al. ${ }^{17}$ & 2019 & 33 & $\operatorname{COLD}(\mathrm{LC})$ & MTAFillapex & + & + & + & + & & \\
\hline 15. Marinova-Takorova M, et al. ${ }^{18}$ & 2019 & 33 & $\operatorname{COLD}(\mathrm{HC})$ & MTAFillapex & + & + & + & + & & \\
\hline 16. Eymirli A, et al. ${ }^{8}$ & 2019 & 60 & $\operatorname{COLD}(\mathrm{HC})$ & BC Sealer & & + & & & & \\
\hline 17. Pedulla E, et al..$^{20}$ & 2019 & 72 & $\operatorname{COLD}(\mathrm{HC})$ & $\begin{array}{l}\text { BioRoot, Guttaflow } \\
\text { Bioseal }\end{array}$ & & + & & & & + \\
\hline
\end{tabular}


and Tornado Brush were significantly better than syringe irrigation in removing BioRoot RCS, with no difference between them. ${ }^{20}$

All the studies differed in the factors related to the retreatment that they examined. Some investigate the ability to reach WL and AP. Others measure the time required for completing the retreatment. Almost all of them examine the cleanness of the canal wall after the retreatment procedure.

The percentage of reaching WL and AP in cases with BCS is $100 \%{ }^{5,6,9,11,15}$ when the sealer is used in conjunction with gutta-percha point at WL, and $0 \%$ when it is used alone as a filling material ${ }^{8}$. When the GP point is positioned short of WL there are different results. ${ }^{9,11}$

As for time consumption MTA Fillapex is removed the fastest. ${ }^{4}$ Required time is similar if a $2 \%$ or a $4 \%$ gutta-percha cone is used. ${ }^{8}$ When the GP cone is positioned short in the canal the time required for regaining WL is significantly greater than if it is positioned at WL. ${ }^{9}$ Both R-Endo and ultrasonic tips perform similarly in terms of operating time. ${ }^{14}$ Reciprocating files reach WL faster than rotary and BCS takes more time to be removed than PCS. ${ }^{12}$

Clean canal walls are achieved in none of the samples. ${ }^{3-7,9,12-20}$ Chloroform, Eucalyptol and Endosolv E are effective at softening gutta-percha and MTA Fillapex, whereas Endosolv $\mathrm{R}$ is not. ${ }^{11}$

In Table 1, studies are presented in chronological order and the tools for removal of root canal filling are summarised. Only articles that examine the retreatability of bioceramic sealers are included in the table.

\section{CONCLUSIONS}

1. Hand and machine-driven endodontic files are not efficient in complete removal of root filling material during NSER.

2. Use of ultrasonics, solvents and PIPS facilitates the removal of the remaining filling material after the retreatment procedure with hand and/or machine driven instruments, but absolute removal is not predictably achievable.

3. Due to differences in the methodologies the results from the studies vary a lot. Nevertheless complete removal of sealer was not observed in any of the cases. There is still no efficient protocol proposed for removal of BCS in the clinical practice.

\section{REFERENCES}

1. Lee S, Monsef M, Torabinejad M. Sealing ability of a mineral trioxide aggregate for repair of lateral root perforations. J Endod 1993; 19(11): 541-4.

2. Wilcox L, Krell K, Madison S, et al. Endodontic retreatment: evaluation of gutta-percha and sealer removal and canal reinstrumentation. J Endod 1987; 13(9): 453-9.

3. Ersev H, Yilmaz B, Dinçol ME, et al. The efficacy of ProTaper univer- sal rotary retreatment instrumentation to remove single gutta-percha cones cemented with several endodontic sealers. Int Endod J 2012; 45: 756-62.

4. Uzunoglu E, Yilmaz Z, Sungur DD, et al. Retreatability of root canals obturated using gutta-percha with bioceramic, MTA and resin-based sealers. Iran Endod J 2015; 10: 93-8.

5. Kim H, Kim E, Lee SJ, et al. Comparisons of the retreatment efficacy of calcium silicate and epoxy resin-based sealers and residual sealer in dentinal tubules. J Endod 2015; 41:2025-30.

6. Kakoura F, Pantelidou O. Retreatability of root canals filled with Gutta percha and a novel bioceramic sealer: A scanning electron microscopy study. J Conserv Dent 2018; 21(6):632-6.

7. Donnermeyer D, Bunne C, Schäfer E, et al. Retreatability of three calcium silicate-containing sealers and one epoxy resin-based root canal sealer with four different root canal instruments. Clin Oral Investig 2018; 22:811-7.

8. Eymirli A, Sungur DD, Uyanik O, et al. Dentinal tubule penetration and retreatability of a calcium silicate-based sealer tested in bulk or with different main core material. J Endod 2019; 45(8): 1036-40.

9. Hess D, Solomon E, Spears R, et al. Retreatability of a bioceramic root canal sealing material. J Endod 2011; 37: 1547-9.

10. Angelus. [Internet] Available from: http://www.angelusdental.com

11. Carpenter MT, Sidow SJ, Lindsey KW, et al. Regaining apical patency after obturation with Gutta-percha and a sealer containing mineral trioxide aggregate. J Endod 2014; 40:588-90.

12. De Siqueira Zuolo A, Zuolo ML, da Silveira Bueno CE, et al. Evaluation of the efficacy of TRUShape and reciproc file systems in the removal of root filling material: An ex vivo micro-computed tomographic study. J Endod 2016; 42: 315-9.

13. Oltra E, Cox TC, LaCourse MR, et al. Retreatability of two endodontic sealers, EndoSequence BC sealer and AH plus: A microcomputed tomographic comparison. Restor Dent Endod 2017; 42: 19-26.

14. Simsek N, Keles A, Ahmetoglu F, et al. Comparison of different retreatment techniques and root canal sealers: A scanning electron microscopic study. Braz Oral Res 2014; 28: S1806-8324.

15. Agrafioti A, Koursoumis AD, Kontakiotis EG. Re-establishing apical patency after obturation with gutta-percha and two novel calcium silicate-based sealers. Eur J Dent 2015; 9: 457-61.

16. Marinova-Takorova M, Radeva E, Kisyova I, et al. Effectiveness of different retreatment techniques in the removal of gutta-percha cones and bioceramic-based root canal sealer in the different parts of the root canal. MedInform 2018; 5(1): 713-23.

17. Marinova-Takorova M, Radeva E, Kisyova I, et al. Retreatment of teeth filled with lateral compaction technique and bioceramicbased sealer - comparison of time needed and effectiveness of different retreatment techniques. J of IMAB 2019; 25(1): 2373-78.

18. Marinova-Takorova M, Radeva E, Kisyova I, et al. Retreatment of teeth filled with single cone technique and MTA based sealer comparison of the effectiveness of different retreatment techniques (in vitro study). J of IMAB 2019; 25(1): 2379-83.

19. Suk M, Bago I, Katić M, et al. The efficacy of photon-initiated photoacoustic streaming in the removal of calcium silicate-based filling remnants from the root canal after rotary retreatment. Lasers Med Sci 2017; 32: 2055-62.

20. Pedulla E, Abiad R, Conte G, et al. Retreatability of two hydraulic calcium silicate-based root canal sealers using rotary instrumentation with supplementary irrigant agitation protocols: A laboratory-based micro-computed tomographic analysis. IEJ 2019; 52(9): 1377-87. 


\title{
Биокерамические эндодонтические герметики при повторном лечении - обзор
}

\author{
Костадин И. Жеков, Весела П. Стефанова \\ Кафедра оперативной стоматологии и эндодонтии, Факультет дентальной медицинь, Медицинский университет - Пловдив, Пловдив, \\ Болгария
}

Адрес для корреспонденции: Костадин И. Жеков, Кафедра оперативной стоматологии и эндодонтии, Факультет дентальной медицины, Медицинский университет - Пловдив, бул. „Христо Ботев“ № 3, 4002 Пловдив, Болгария; E-mail: ko.zhekov@gmail.com; Tel.: +359885995821

Дата получения: 28 октября 2019 Дата приемки: 26 декабря 2019 Дата публикации: 30 июня 2020

Образец цитирования: Zhekov KI, Stefanova VP. Retreatability of bioceramic endodontic sealers: a review. Folia Med (Plovdiv) 2020;62(2):258-64. doi: 10.3897/folmed.62.e47690.

\section{Абстракт}

В 2009 году на рынке был представлен новый тип эндодонтических герметиков. Так называемые «биокерамические» герметики являются многообещающей альтернативой существующему «золотому стандарту» материалов для пломбирования корневых каналов. Сейчас, спустя десятилетие, мало что известно о возможности удаления этих герметиков в случаях безоперационного эндодонтического повторного лечения (БОЭПЛ). Существует ограниченное количество статей, представляющих такую информацию. Часто используемые ручные файлы не эффективны для полного удаления герметика с основных стенок канала. Инструменты с механическим приводом - намного более простая и быстрая альтернатива ручным, но они всё ещё не могут обеспечить полное удаление. Хотя ультразвук можно применять только в прямой части основного канала, он повышает эффективность удаления пломбы. PIPS (фотоакустическое потоковое излучение, инициируемое фотонами) - еще один способ улучшить удаление биокерамики. Растворители, такие как хлороформ и апельсиновое масло, эффективны при смягчении гуттаперчи, но не и биокерамики. В данной статье рассматриваются имеющиеся научные данные по удалению биокерамических материалов в контексте БОЭПЛ.

\section{Ключевые слова}

биокерамика, повторное лечение, обзор 